\title{
Changes in astigmatism after cataract extraction and intraocular lens implantation in children
}

\begin{abstract}
Purpose To evaluate the post-operative changes in astigmatism in pseudophakic eyes in children.

Methods The charts of children who had undergone surgery for non-traumatic cataract were retrospectively reviewed. In 10 eyes with astigmatism of $3.0 \mathrm{D}$ or more, the refraction was tested and recorded at 1 week, 3 months and 5 months post-operatively.

Results Mean astigmatism 1 week postoperatively was $6.2 \pm 2.7 \mathrm{D}$ (range 3.0-11.0 D). Thereafter, the astigmatic component of the refractive error underwent a spontaneous steady decline, reaching a mean value of $1.2 \pm$ 1.1 D (range 0-3.0 D) 5 months after surgery. The change in the difference between the mean values at 1 week and at 5 months was statistically significant ( $p=0.0002$ ).

Conclusions Children who underwent cataract extraction and intraocular lens implantation showed a significant spontaneous reduction in astigmatism post-operatively. This finding suggests that there is no need to remove sutures in order to achieve reduction of postoperative astigmatism in these children.
\end{abstract}

Key words Astigmatism, Cataract extraction

\section{A. Spierer \\ M. Shelah \\ Goldschleger Eye Institute \\ Sheba Medical Center \\ Tel-Hashomer \\ Sackler Faculty of Medicine Tel-Aviv University, Israel}

Abraham Spierer, MD Goldschleger Eye Institute Sheba Medical Center 52621 Tel-Hashomer, Israel Tel: +972 35302874 Fax: +97235302822

Received: 4 November 1998 Accepted: 26 January 1999

\section{Materials and methods}

The charts of 27 children (45 eyes) who underwent surgery for congenital cataract between 1992 and 1994 were reviewed. All eyes with astigmatism of $3.0 \mathrm{D}$ or more 1 week after surgery were included in the study. There were no other ocular or systemic abnormalities in the study population. All patients had undergone a uniform procedure for extracapsular cataract extraction and intraocular lens implantation. A fornix-based conjunctival flap had been formed, and after mild local diathermy a partialthickness incision was made at the limbus with a no. 64 Beaver blade. A keratome was introduced into the anterior chamber at the limbus at 2 and 10 o'clock. An anterior chamber maintainer (Visitec) was used and capsulorhexis was performed with a bent 25 gauge needle. All lens material was aspirated with the Anis aspirating cannula (Storz).

Posterior capsulotomy and anterior vitrectomy were performed with the ocutome

(Coopervision) in all cases but two cases (nos. 4 and 6) (Table 1). The corneal incision was enlarged by the use of scissors (Storz), with the blades rotated so that bevelled cuts were made. An intraocular lens (Hanita) was implanted in the bag. The limbal incision was closed with five or six interrupted 10/0 Mersilene sutures (Ethicon), and the conjunctiva was replaced without suturing. All operations were performed by the same surgeon (A.S.), using the same surgical technique.

The refractive error of the operated eye was tested (as part of the complete eye examination) at 1 week and then on average every 1-2 months for 6 months, after dilation of the pupil with $0.5 \%$ tropicamide. All refractive errors were corrected with spectacles 1 month after surgery, and treatment for amblyopia was instituted when indicated. No sutures were removed during follow-up.

\section{Results}

When examined 1 week after surgery, 10 eyes (9 children) had astigmatic error of $3.0 \mathrm{D}$ or more, and were therefore included in the study. The age range of these children was 2.5-11 


\begin{tabular}{lcccc}
\hline & & \multicolumn{3}{c}{ Post-operative astigmatism } \\
\cline { 2 - 5 } Eye no. & Age (years) & At 1 week & At 3 months & At 5 months \\
\hline 1 & 8.5 & $-3.0 \times 165^{\circ}$ & $-3.0 \times 180^{\circ}$ & 0 \\
2 & 2.5 & $-6.0 \times 10^{\circ}$ & $-4.0 \times 180^{\circ}$ & $-1.5 \times 165^{\circ}$ \\
3 & 11 & $-6.0 \times 15^{\circ}$ & $-4.0 \times 10^{\circ}$ & $-3.0 \times 180^{\circ}$ \\
4 & 11 & $-6.0 \times 10^{\circ}$ & $-2.0 \times 180^{\circ}$ & $-1.0 \times 180^{\circ}$ \\
5 & 5.5 & $-11.0 \times 150^{\circ}$ & 0 & 0 \\
6 & 7 & $-3.0 \times 150^{\circ}$ & $-1.0 \times 160^{\circ}$ & $-1.0 \times 45^{\circ}$ \\
7 & 7 & $-8.0 \times 180^{\circ}$ & 0 & 0 \\
8 & 4 & $-3.0 \times 150^{\circ}$ & 0 & $-1.0 \times 90^{\circ}$ \\
9 & 4 & $-7.0 \times 180^{\circ}$ & $-6.0 \times 145^{\circ}$ & $-3.0 \times 130^{\circ}$ \\
10 & 6 & $-9.0 \times 180^{\circ}$ & $-5.0 \times 175^{\circ}$ & $-1.5 \times 70^{\circ}$ \\
Mean $\pm \mathrm{SD}$ & 6.7 & $-6.2 \pm 2.7$ & $-2.5 \pm 2.2$ & $-1.2 \pm 1.1$ \\
\hline
\end{tabular}

years. In all cases the surgical and post-operative course was uneventful, and no complications were noted.

One week after surgery mean astigmatism was $6.2 \pm$ $2.7 \mathrm{D}$. The mean refractive error declined to $2.5 \pm 2.2 \mathrm{D}$ at 3 months post-operatively, and to $1.2 \pm 1.1 \mathrm{D}$ at 5 months post-operatively. No significant further decline was recorded 1 year after surgery. The refractive errors of the individual patients are summarised in Table 1.

The observed changes in astigmatism were statistically significant: $p=0.0035$ between 1 week and 3 months, $p=0.0145$ between 3 months and 5 months, and $p=0.0002$ between 1 week and 5 months.

\section{Discussion}

Post-operative corneal astigmatism is an integral part of the refractive error measured after cataract surgery in both adults and children. The amount of immediate postoperative astigmatism and its subsequent changes are affected by factors such as the surgical technique, type of suture used, and the experience of the surgeon. ${ }^{1-3,11}$ The present series was comprised of children who had undergone surgery performed by the same surgeon using the identical surgical technique, sutures and intraocular lens type in each case. Any changes that occurred in this uniformly operated group in astigmatism could, therefore, be considered as spontaneous, and not affected by any specific surgically dependent variable. Most of the eyes in the series had post-operative with-the-rule astigmatism and in three the astigmatism shifted towards against-the-rule. This shifting phenomenon has previously been described in adults. $^{10}$

The finding of post-operative astigmatism is important, especially in children, because of its adverse effect on vision development and the attendant risk of amblyopia. ${ }^{12}$ In adults, a few months of delay in refractive error correction has no effect on the final visual acuity, whereas in children precise refractive optical correction must be made as soon as possible.

Accordingly, all our patients received their refractive correction after surgery, and any further changes in astigmatism were promptly followed by changes in the refractive correction. On the other hand, whereas postoperative surgical astigmatism in adults can be corrected by removal of one or more sutures in a simple office procedure ${ }^{6,7}$ in children the procedure usually requires general anaesthesia. Only mild spontaneous regression of post-operative astigmatism has been described in adults. Without suture cutting, mean changes of only 0.5 $\mathrm{D}^{4}$ and $1.25 \mathrm{D}^{5}$ were reported during the first year after cataract surgery. In our paediatric series, an average spontaneous decline in astigmatism of $5.0 \mathrm{D}$ was observed 5 months after surgery. The following factors might have contributed to this marked spontaneous regression in post-operative astigmatism: (1) The ocular tissues in children exhibit a high degree of elasticity. In adults, wound compression caused by the sutures does not change over time, whereas in children, because of the elasticity of the cornea and sclera, the tissue tension may spread evenly to neighbouring areas, reducing the amount of astigmatism. (2) Growth of the globe continues in children (but not in adults) under constant centrifugal intraocular pressure, and results in a more spherical growth of the eye, thereby diminishing the amount of astigmatism. This factor may be particularly important in young children.

Correction of refractive errors in children is essential in order to avoid development of amblyopia.

Astigmatism should therefore be promptly treated, and this is normally done either by adequate optical correction or by suture removal. The findings of the present study strongly suggest that removal of sutures is not required, since ocular astigmatism spontaneously regresses a few months after surgery. This also eliminates the need for the general anaesthesia that is usually necessary for suture removal in children.

We are currently using a scleral tunnel incision and comparing the results with those obtained using a corneal incision. It was recently reported ${ }^{3}$ that the mean astigmatism 1 month after surgery in adult eyes operated on through a corneal incision was significantly higher than in eyes operated on through a scleral incision. However, the mean final astigmatism did not differ significantly between these two groups.

\section{References}

1. Jaffe NS. Cataract surgery and its complications, 3rd ed. St Louis: CV Mosby, 1981:92-110. 
2. Seeto R, Ng S, McClellan K, Billson FA. Nonabsorbable suture material in cataract surgery: a comparison of Novafil and nylon. Ophthalmic Surg 1992;23:538-44.

3. Lim TS, Gunning FP, Greve EL. Astigmatism following cataract surgery: comparison of a scleral and a corneal incision in a mixed group of patients with and without glaucoma. Int Ophthalmol 1992;16:177-83.

4. Kronish JW, Forster RK. Control of corneal astigmatism following cataract extraction by selective suture cutting. Arch Ophthalmol 1987;105:1650-5.

5. Richards SC, Brodstein RS, Richards WL, Olson RJ, Combe $\mathrm{PH}$, Crowell KE. Long-term course of surgically induced astigmatism. J Cataract Refract Surg 1988;14:270-6.

6. Rowan PJ. Corneal astigmatism following cataract surgery. Ann Ophthalmol 1978;10:231-4.

7. Talamo JH, Stark WJ, Gottsch JD, Goodman OF, Pratzer K, Cravy TV, et al. Natural history of corneal astigmatism after cataract surgery. J Cataract Refract Surg 1991;17:313-8.
8. Axt JC. Longitudinal study of postoperative astigmatism. J Cataract Refract Surg 1987;13:381-8.

9. Storr-Paulsen A, Vangsted P, Perriard A. Long-term natural and modified course of surgically induced astigmatism after extracapsular cataract extraction. Acta Ophthalmol (Copenh) 1994;72:617-21.

10. Stanford MR, Fenech T, Hunter PA. Timing of removal of sutures in control of post-operative astigmatism. Eye 1993;7:143-7.

11. Bigar F. Astigmatism following cataract surgery: comparison following' wound closure with nylon suture and Mersilene. Klin Monatsbl Augenheilkd 1990;196:314-5.

12. Fulton AB, Dobson V, Salem D, Mar C, Petersen RA, Hansen RM. Cycloplegic refractions in infants and young children. Am J Ophthalmol 1980;90:239-47. 